\title{
Anabases
}

ANABASES Traditions et réceptions de l'Antiquité

16 | 2012

Varia

\section{Benjamin ACOSTA-HUGHUES, Christophe CUSSET, Yannick DURBEC et Didier PRALON (éd.), Homère revisité. Parodie et humour dans les réécritures homériques}

\section{Alain Ballabriga}

\section{OpenEdition}

\section{Journals}

Édition électronique

URL : http://journals.openedition.org/anabases/3995

DOI : 10.4000/anabases.3995

ISSN : 2256-9421

Éditeur

E.R.A.S.M.E.

Édition imprimée

Date de publication : 1 octobre 2012

Pagination : 297-298

ISSN : 1774-4296

\section{Référence électronique}

Alain Ballabriga, «Benjamin acosta-hughues, Christophe cusset, Yannick durbec et Didier pralon (éd.), Homère revisité. Parodie et humour dans les réécritures homériques ", Anabases [En ligne], 16 | 2012, mis en ligne le 01 octobre 2012, consulté le 20 septembre 2020. URL : http://journals.openedition.org/ anabases/3995; DOI : https://doi.org/10.4000/anabases.3995

Ce document a été généré automatiquement le 20 septembre 2020

(c) Anabases 


\title{
Benjamin ACOSTA-HUGHUES, Christophe CUSSET, Yannick DURBEC et Didier PRALON (éd.), Homère revisité. Parodie et humour dans les réécritures homériques
}

\author{
Alain Ballabriga
}

\section{RÉFÉRENCE}

Benjamin ACOSTA-HUGHuEs, Christophe cusSET, Yannick DURBEC et Didier PRALON (éd.),

Homère revisité. Parodie et humour dans les réécritures homériques,

Besançon, Presses universitaires de Franche-Comté, 2011, 224 p.

21 euros / ISBN 978-2-84867-346-2.

1 Ce volume rassemble les actes du colloque international «Réécritures et parodies d'Homère dans la littérature grecque d'époque hellénistique et tardive" (Maison Méditerranéenne des Sciences de l'Homme, Aix-en-Provence, 30 et 31 octobre 2008). Les douze contributions réunies dans ce volume sont classées dans l'ordre alphabétique des noms des contributeurs et portent en fait sur des textes qui s'étendent de l'époque archaïque, avec le Margitès (fin vile-début vi ${ }^{\mathrm{e}}$ s. av. J.-C.) jusqu'à l'antiquité tardive, avec les Dionysiaques de Nonnos de Panopolis ( $v^{e} s$. ap. J.-C.), en passant par la poésie hellénistique et la prose de Plutarque et Lucien. De ces études, je retiendrai quelques points saillants, de façon à faire sentir la diversité des problèmes évoqués et les éléments de récurrence dans des œuvres que je présenterai dans l'ordre chronologique.

2 L'étude sur le Margitès se présente sous la forme d'un commentaire philologique des fragments réunis dans une édition récente. Le « héros » de ce poème, où se mêlaient hexamètres dactyliques et trimètres iambiques et dont on ne possède plus que quelques 
misérables fragments, portait un nom dérivé de margos "fou». C'était un benêt agissant en toute occasion de façon stupide, un " anti-héros » en somme. À la différence de ce qui peut s'observer à l'époque hellénistique, il n'est pas sûr que l'auteur du Margitès ait voulu faire une parodie des textes épiques tels qu'on les lisait depuis l'époque classique. Selon moi il s'agirait plutôt d'une satire des valeurs de l'univers héroïque couchée dans le langage commun des traditions orales.

Différemment le Combat des grenouilles et des rats (Batrachomyomachie), parodiant des textes fixés par l'écriture, est une œuvre bien plus tardive. Mais peut-on aller jusqu'à voir en Lucien son auteur? Certains traits de langue tardifs se retrouvent par exemple chez le géographe Strabon (64 av.-24 ap. J.-C.). Mais ce poème (300 hexamètres) semble avoir été connu bien plus tôt, dès le II $^{\mathrm{e}} \mathrm{s}$. av. J.-C. Il vaut mieux donc admettre que ce poème d'époque hellénistique a pu être remanié à l'époque romaine, selon un processus particulier qui prolonge à l'époque hellénistique et romaine un phénomène de variation textuelle propre à l'époque archaïque.

4 Avec les poètes hellénistiques du $\mathrm{III}^{\mathrm{e}} \mathrm{s}$. av. J.-C. (Théocrite, Callimaque, Lycophron), on rencontre des problèmes plus complexes et spécifiques. Dans l'Epithalame d'Hélène de Théocrite, l'ironie à l'égard de Ménélas renvoie à la fois à la figure assez peu héroïque de l'époux d'Hélène dans l'épopée et à une tradition satirique que l'on trouvait dans les chants nuptiaux de Sappho, qui reflétaient à leur tour une tradition culturelle (moqueries dans les fêtes de mariage) beaucoup plus large et dans laquelle s'inscrit la littérature aussi bien archaïque qu'hellénistique.

$5 \quad$ L'Alexandra de Lycophron est un monologue dramatique de 1474 trimètres iambiques dans lequel l'esclave qui surveillait Alexandra /Cassandre rapporte ses prophéties à son père Priam, roi de Troie. Cette perspective troyenne explique que les héros grecs soient dépouillés du prestige de l'épopée et qu'Ulysse en particulier apparaisse comme un «pauvre homme».

6 C'est une veine franchement obscène que l'on trouve dans certaines épigrammes d'époque romaine recueillies dans l'Anthologie grecque. Par exemple le thème du jugement des trois déesses (Héra, Athéna, Aphrodite) par le troyen Pâris est réutilisé à propos de trois hétaïres nues dont on compare les fesses, voire les parties génitales. Ce filon obscène, qui faisait froncer les sourcils des beaux esprits, s'observe en fait depuis le Margitès et apparaissait aussi dans la peinture : le stoïcien Chrysippe faisait état d'un tableau représentant Héra faisant une fellation à Zeus, ce qui poussait à l'extrême la liberté des poètes grecs à l'égard de leurs dieux.

Beaucoup plus sage (même chez un Lucien), la prose d'époque romaine présente deux cas, eux-mêmes contrastés, de réception humoristique des poèmes homériques. Dans son Gryllos, Plutarque donne la parole à l'un des compagnons d'Ulysse transformés en porc par la magicienne Circé. Ce Gryllos, dont le nom évoque le grognement du cochon, refuse de redevenir homme car la condition animale lui paraît préférable. Ce renversement humoristique des données épiques renvoie au fait que Plutarque s'intéressait beaucoup aux animaux.

8 Quant à Lucien, dans son Charon ou les contemplateurs (episkopountes), dialogue entre le dieu messager Hermès et Charon, le passeur des morts en visite dans le monde des vivants, il combine sa critique habituelle des vanités des biens terrestres et de la croyance aux fables des poètes avec une parodie de la poésie homérique et du Poète lui- 
même : Homère, pris par le mal de mer sur la barque de Charon, vomit des morceaux d'épopée, ce qui permet à Charon d'égaler Hermès en science poétique.

9 À la fin de l'Antiquité, Nonnos de Panopolis pousse à son terme le raffinement hellénistique dans une vaste épopée, les Dionysiaques, qui narre les aventures du dieu Dionysos et en particulier son expédition contre les Indiens. Par exemple l'épisode d' Arès trompé au chant 29 (vv. 325-381) combine à la fois des thèmes de l'Iliade (Zeus trompé du chant XIV) et de l'odyssée (adultère d'Arès et d'Aphrodite, chant viII) : Arès est détourné du combat et part en quête d'Aphrodite qui est revenue auprès de son époux Héphaistos. Cette forme d'humour, qui évoque à la fois Callimaque et Lucien, renvoie plus profondément au projet poétique d'ensemble de Nonnos: l'épopée homérique ne saurait égaler l'ampleur des guerres dionysiaques aux Indes.

\section{AUTEURS}

\section{ALAIN BALLABRIGA}

Université de Toulouse (UTM)

a.ballabriga@gmail.com 